\title{
A reconstrução da indústria brasileira: a conexão entre o regime macroeconômico e a política industrial*
}

\author{
The reconstruction of the Brazilian industry: the connection \\ between the macroeconomic regime and the industrial policy
}

LUIZ CARLOS BRESSER-PEREIRA

ANDRÉ NASSIF

CARMEM FEIJÓ**

RESUMO: Este artigo, de cunho eminentemente analítico, mostra que no âmbito da política macroeconômica é necessária consistência entre as políticas monetária, fiscal, cambial e salarial para viabilizar taxas de juros reais médias inferiores às taxas de retorno médias sobre o capital, taxas de câmbio reais competitivas (em torno da taxa de "equilíbrio industrial") e taxas de salários que evoluam de acordo com o crescimento da produtividade, condições para que se assegure o crescimento econômico sobre bases sustentáveis. Já com respeito à política industrial é preciso perseguir estratégias de diversificação produtiva, notadamente no setor manufatureiro e nos segmentos tradable do setor de serviços, mediante a identificação de prioridades estratégicas tanto nas cadeias produtivas, segmentos e setores próximos à base de vantagem comparativa preexistente, como naqueles mais próximos à fronteira tecnológica internacional. Embora os argumentos analíticos favoreçam a estratégia de diversificação produtiva, esta não deve ser confundida com semiautarquia, o que significa que as cadeias e setores que não sejam foco da política industrial devem ter alíquotas de importação zero ou próximas de zero.

PALAVRAS-CHAVE: reindustrialização; convergência econômica; regime macroeconômico; política industrial.

\footnotetext{
* Artigo preparado para a Mesa Especial "Estratégias para a reindustrialização", organizado pela Associação Keynesiana Brasileira (AKB), e apresentado no $43^{\circ}$ Encontro dos Centros de Pós-Graduação em Economia (ANPEC), realizado em Florianópolis (SC), 8 e 11 de dezembro de 2015. Os autores agradecem os comentários de David Kupfer, Jorge Arbache, Luiz Fernando de Paula, Nelson Marconi e Marcos Lisboa, isentando-os, como de praxe, dos erros remanescentes.

"* Professor Emérito da Fundação Getulio Vargas (FGV-SP). E-mail: bresserpereira@gmail.com; Professor da Universidade Federal Fluminense e economista do BNDES. E-mail: andrenassif27@gmail.com; Professora da Universidade Federal Fluminense. E-mail: cbfeijo@gmail.com.

Submetido: 19/Agosto/2014; Aprovado: 09/Outubro/2015.
} 
ABSTRACT: This paper is predominantly analytical. Concerning the macroeconomic regime, we propose more consistency between monetary, fiscal, exchange rate and wage policies. Such consistency is to provide sustainable long-term economic growth with structural change. Also, it is to make it feasible to not only maintain average real interest rates below the average real return rates on capital, but also competitive real exchange rates (i.e., marginal undervalued real exchange rates) and real wages that increase in step with productivity growth. This will help guarantee sustainable economic growth. As for industrial policy, theoretical and empirical evidence suggests the need to pursue strategies that diversify production, especially within the manufacturing sector as well as within tradable segments of the service sector. Although theoretical arguments are favorable to strategies that diversify production in countries that did not manage to catch up with developed countries, such strategies should avoid semi-autarky policies, which means that production chains, segments and sectors that are not the focus of industrial policy should have zero import tariffs, or close to zero.

KEYWORD: reindustrialization; catching up; macroeconomic regime; industrial policy.

JEL Classification: O1; O23; O24; O25.

No meio do caminho tinha uma pedra tinha uma pedra no meio do caminho tinha uma pedra

tinha uma pedra no meio do caminho

Carlos Drummond de Andrade, "No meio do caminho", Alguma poesia, São Paulo, Cia. das Letras, 2013 [1ª edição: 1930]

\section{INTRODUÇÃO}

Para além dos obstáculos de nossa vida pessoal, familiar e social, os famosos versos de Drummond, contidos na epígrafe que abre este artigo, podem muito bem refletir os diversos entraves que têm impedido o Brasil, desde o início da década de 1980, de superar o processo de semiestagnação que se abateu sobre sua economia, impedindo-a de manter taxas sustentáveis de crescimento e continuar o processo de mudanças estruturais necessárias para alcançar a convergência econômica (catching up) compatível com os padrões de renda per capita e de bem-estar dos países desenvolvidos. Esses obstáculos não têm sido poucos: crise da dívida externa na década de 1980; inflação crônica que se estendeu do início dessa década até quase toda a primeira metade da década de 1990; taxas de juros reais anormalmente elevadas e bem superiores à média internacional; e taxas de câmbio reais cíclica e cronicamente apreciadas, dentre outros.

No caso brasileiro, em particular, é lícito afirmar que o país conseguiu promover sua industrialização, mas não logrou completar seu processo de catching $u p$, devido, principalmente, à desindustrialização prematura que se iniciou ainda na 
metade da década de 1980, mas se intensificou a partir da década de 2000 . Ao longo de seu processo de industrialização, tido como marco inicial o início da década de $1930,{ }^{1}$ o Brasil praticamente esgotou as possibilidades de mudanças estruturais no sentido de Lewis (1954) - ou seja, de transferência de recursos produtivos (especialmente força de trabalho) do setor tradicional agrícola para o setor industrial capitalista. No entanto, em vista do processo de desindustrialização prematura, ainda há potencial para promover mudanças estruturais no sentido de Kaldor (1966), especialmente as destinadas a conferir ao setor manufatureiro brasileiro (a "indústria de transformação", segundo a terminologia do IBGE) status ainda não alcançado de indústria madura. ${ }^{2}$

No Brasil, três políticas habituais nos países em desenvolvimento e uma não política causaram a sobreapreciação cíclica e crônica (no longo prazo) da taxa de câmbio, desestimularam o investimento privado e desencadearam, inicialmente, e agravaram, nas duas últimas décadas, o processo de desindustrialização prematura: i) as três políticas habituais foram: a política de altas taxas de juros (o enorme diferencial entre as taxas de juros internas e internacionais, o qual induz a excessivas entradas líquidas de capitais), a insistência na estratégia de financiar o crescimento com poupança externa (isto é, em incorrer em déficits em conta-corrente), e o uso da taxa de câmbio como âncora contra a inflação; ii) a não política foi, com a liberalização comercial relativamente rápida e a abertura financeira, entre 1990 e 1994, o desmantelamento inconsciente do mecanismo que neutralizava a doença holandesa. Além de apreciarem no longo prazo a taxa de câmbio e desestimularem seriamente o investimento privado, essas quatro causas implicaram a perda da capacidade do país de realizar uma política cambial que mantivesse a taxa de câmbio real competitiva. Como, além disso, desde os anos 1980, a poupança pública tornou-se negativa, o Estado ficou, por conseguinte, incapaz de financiar uma parcela razoável do investimento total brasileiro, que deve ser de $20 \%$ do total, à luz da experiência internacional. Com isso, teremos, então, explicadas as baixas taxas de investimento e de crescimento econômico do país.

Logo, para promover a reindustrialização e redirecionar o Brasil em sua trajetória de catching up, não basta apenas a adoção de políticas industriais e tecnológicas consistentes, mas também que estas estejam estreitamente articuladas com o regime macroeconômico. Por regime macroeconômico entendemos a adoção e implementação de políticas monetária, fiscal, cambial e salarial consistentes, cujo objetivo é não somente manter a estabilidade de preços, como também permitir que a economia, em vez de seguir trajetórias do tipo stop and go - como tem sido o caso do Brasil nos últimos 35 anos - consiga realizar seu potencial de crescimento econômico de forma sustentável. Como mostraremos adiante, a consistência do regime macroeconômico de um país em desenvolvimento como o Brasil, que almeja a reindustrialização e a superação dos obstáculos "drummondianos" para a perse-

\footnotetext{
${ }^{1}$ Ver Furtado (1959), Tavares (1963) e Bresser-Pereira (1968, 2014).

${ }^{2}$ Essa discussão será retomada e um pouco mais detalhada nas seções seguintes.
} 
cução do catching up, requer os seguintes arranjos concernentes à política econômica lato sensu: i) uma política monetária que, em consonância com as propostas emanadas do debate internacional recente (ver Blanchard, 2010, 2013; Yellen, 2014), persiga não apenas metas de inflação baixas e estáveis, mas também metas de crescimento econômico sustentáveis mediante a suavização das flutuações cíclicas. ${ }^{3}$ Somente um regime de metas de inflação flexíveis será capaz de viabilizar taxas de juros reais médias inferiores às taxas de retorno médias sobre o capital, uma das condições (embora não exclusiva) para aumentar a taxa de investimento na economia brasileira; ii) uma política fiscal que continue embasada na Lei de Responsabilidade Fiscal, evitando o chamado "populismo fiscal", ${ }^{4}$ mas que resgate seu caráter contracíclico, de tal sorte que, ao perseguir maiores superávits primários nos ciclos expansivos, os policy-makers possam contar com maior espaço de política (policy space) para reduzi-los ou mesmo operar com déficits fiscais primário nos ciclos recessivos; iii) a adoção de instrumentos de política cambial que impeçam a tendência cíclica e crônica de apreciação da moeda brasileira em termos reais e os respectivos déficits em conta-corrente; tal tendência, por ter acarretado a elevação artificial dos salários acima do crescimento da produtividade do trabalho na última década (ou seja, a elevação do índice comparativo do custo unitário do trabalho), tem reduzido adicionalmente a competitividade das empresas locais e minado a adoção das tecnologias necessárias para manter essa competividade no plano tecnológico; e iv) o aumento da poupança pública que permita ao Estado responsabilizar-se por cerca de $20 \%$ do investimento total do país e, ao mesmo tempo, manter a responsabilidade fiscal.

Essas forças estruturais e conjunturais que deflagram a tendência cíclica e crônica de apreciação da moeda doméstica em termos reais não afetam apenas o Brasil, mas diversos outros países em desenvolvimento que sofrem, simultaneamente, a doença holandesa e os impactos decorrentes dos enormes influxos líquidos de capitais. Apenas para citar dois países que fazem parte do grupo dos BRICS (Brasil, Rússia, Índia, China e África do Sul), tanto o rublo russo como o rand sul-africano têm apreciado ciclicamente desde a década de 2000, devido à fortíssima doença holandesa (caso especialmente da Rússia) e aos elevados influxos líquidos de capitais externos (caso da África do Sul, que, como o Brasil, sofre também de doença holandesa). ${ }^{5}$

\footnotetext{
${ }^{3}$ A tais objetivos da política monetária, Yellen (2014) denomina "regime de metas de inflação flexíveis" (RMI), mas nossa proposta é que tal flexibilidade abarque também a mudança do modus operandi do RMI no Brasil, como será defendido posteriormente.

${ }^{4}$ Essa expressão é recorrentemente usada por um dos autores deste artigo (Bresser-Pereira, 2010, 2014).

${ }^{5}$ De acordo com a base de dados referentes aos índices de taxas de câmbio reais efetivas (isto é, com relação a uma cesta internacional de moedas conversíveis), do Bank of International Settlements, em maio de 2015 o rublo russo estava cerca de $70 \%$ apreciado em relação à taxa de câmbio média de 2000. Com respeito à África do Sul, Arezki et al. (2012, p. 1) comentam que, "a enorme tendência à apreciação do rand sul-africano é explicada tanto pela volatilidade do preço do ouro (um dos principais itens de exportação do país), como pelos elevados influxos líquidos de capital, parte significativa dos
} 
Com relação à questão da taxa de salários, embora os indicadores apontem que a mesma cresceu (em termos médios anuais) no Brasil consistentemente acima da produtividade, nossa proposta não contém qualquer medida mirabolante, para dizer o mínimo. Entendemos que, num regime democrático, não cabe ao governo interferir nas negociações salariais entre empresários e sindicatos, exceto quando o objetivo for a mediação de conflitos, arbitrada pelos tribunais regionais do trabalho, como já prevê a legislação brasileira. Sendo assim, nossa proposta é que as autoridades econômicas, também mediante um regime macroeconômico consistente, possam criar as condições para o crescimento sustentado da produtividade do trabalho no Brasil.

Em que pese em todas as críticas que se possam fazer às políticas industriais recentes no Brasil - por exemplo, falta de seletividade na escolha de segmentos e setores, o que fortalece a suspeita de que tudo é prioritário; excesso de incentivos para setores que não necessitam de benesses governamentais, como o setor automotivo; debilidade dos mecanismos de cobrança de resultados e outras formas de compliance que impeçam a corrupção e atividades rent-seeking etc. -, nosso argumento é que os resultados praticamente nulos alcançados decorrem da ausência de conexão entre o regime macroeconômico e a política industrial propriamente dita. Em termos mais simples, é pouco provável que, se os principais preços macroeconômicos não estiverem em seus respectivos níveis “corretos" (como explicitado nos parágrafos anteriores), a política industrial per se seja capaz de avançar no processo de mudança estrutural e de catching up. Com diz o ditado popular, "uma andorinha apenas não faz verão".

Isso posto, o objetivo do artigo é discutir mecanismos por meio dos quais possa ser resgatada a conexão entre o regime macroeconômico e a política industrial. ${ }^{6}$ Embora esta Introdução e algumas passagens posteriores deste artigo façam referência especial ao Brasil, a discussão aqui proposta é de natureza essencialmente analítica. Subsequentemente, publicaremos um artigo complementar a este, com propostas detalhadas de instrumentos de política orientados para restabelecer a conexão entre o regime macroeconômico e a política industrial no Brasil. Além desta Introdução e de uma breve Conclusão, a segunda seção propõe uma discussão analítica sobre os fenômenos da industrialização, desindustrialização (com ênfase na desindustrialização prematura) e reindustrialização. A terceira seção analisa os problemas analíticos concernentes à conexão entre o regime macroeconômico e a política industrial, ambos orientados para a reindustrialização e o catching up. Ainda que, para fins de argumentação, a seção conte com uma subseção para a

quais é de curtíssimo prazo e de natureza especulativa, o que coloca as autoridades do país diante do enorme desafio de lidar com os problemas decorrentes da abertura da conta de capitais" (tradução livre do original).

\footnotetext{
${ }^{6}$ Note que usamos o termo "resgatada", o que significa que tal conexão, ainda que sujeita a diversas imperfeições, já fora alcançada no passado, especialmente entre a segunda metade da década de 1950 e o final da década de 1970. Houve exceções, de praxe, em alguns subperíodos, mas mesmo estas foram episódicas. Ver, a respeito, Suzigan e Villela (1997).
} 
análise do regime macroeconômico e outra para a política industrial, ambas as esferas de políticas poderão ser discutidas simultaneamente (embora em menor grau) nesta parte do trabalho.

\section{INDUSTRIALIZAÇÃO, DESINDUSTRIALIZAÇÃO E REINDUSTRIALIZAÇÃO: UMA BREVE REFLEXÃO ANALÍTICA}

Passados mais de dois séculos da publicação de A riqueza das nações, de Adam Smith (1776), permanece válida uma das principais teses do autor de que o desenvolvimento econômico ocorre simultaneamente com o aumento da produtividade do trabalho. ${ }^{7}$ É verdade que Smith realçava o papel do sistema de preços relativos (a "mão invisível”), da concorrência entre capitais (como os demais economistas clássicos e Karl Marx) e da especialização (a "divisão social do trabalho") como mecanismos transmissores do incremento da produtividade. Porém, ao postular que a divisão do trabalho é limitada pela extensão do mercado, Smith tinha consciência da relevância tanto da demanda (o tamanho do mercado) como das características tecnológicas da oferta (as economias de escala) como elementos propulsores do aumento da produtividade e do desenvolvimento econômico.

Posteriormente, no entanto, os neoclássicos passaram a conferir maior importância à tese ricardiana de que, mesmo nas questões relacionadas ao desenvolvimento, o principal foco deveria recair na eficiência relativa com que os recursos produtivos (terra, capital, mão de obra e outros “fatores de produção") são mobilizados intra e intersetorialmente. Sendo assim, desde que a interação entre oferta e demanda no longo prazo, intermediada pelo sistema de preços relativos, aloque da forma mais eficiente possível os recursos produtivos existentes na economia, tanto faz que estes migrem assimetricamente para o setor primário, em detrimento dos setores industrial e terciário, ou, inversamente, para os setores industrial e terciário, em detrimento do setor primário. Tendo sido tal resultado produzido pela eficiência do mercado, o mecanismo responsável por ela é considerado um first-best (o laissez-faire). Em outras palavras, de acordo com a tese neoclássica, a agricultura, a indústria e o setor de serviços têm igual peso para produzir avanços absolutos e relativos na produtividade do trabalho e, portanto, para acelerar o processo de convergência de uma economia (catching $u p$ ) em direção a níveis elevados de renda per capita.

Embora tal tese tivesse sido rechaçada pioneiramente por Marx (1887), ao enfatizar o papel do setor de bens de capital e da indústria de "larga escala" como

\footnotetext{
${ }^{7}$ A relação de causalidade entre ambos os fenômenos é uma das controvérsias que separam neoclássicos de estruturalistas. Para os primeiros, é o crescimento da produtividade que deflagra e sustenta o crescimento econômico no longo prazo; para os estruturalistas, o contrário. Este ponto será rediscutido adiante.
} 
motores do progresso tecnológico, ${ }^{8}$ do aumento da produtividade do trabalho e do desenvolvimento econômico, só após a publicação do artigo já considerado clássico de Allyn Young (1928) é que a indústria (e a industrialização) passou a ser incorporada como hipótese fundamental para explicar o avanço da produtividade, do desenvolvimento econômico e do catching up por parte dos autores estruturalistas que se lhe seguiram. Young descontrói a tese de Smith segundo a qual a divisão do trabalho (limitada pelo tamanho preexistente do mercado) facilitaria a invenção de máquinas - as tarefas rotineiras induziriam o empregado a procurar inventar métodos para ficar ocioso durante parte do tempo diário de trabalho -, argumentando que é a própria introdução e difusão de maquinaria (e da indústria, em geral) que, ao criar indivisibilidades tecnológicas no processo produtivo, torna os ganhos pela divisão do trabalho ainda mais limitado pela extensão do mercado. $\mathrm{Ou}$, dito de outra forma, o tamanho do mercado é crucial para viabilizar economias de escala compatíveis com a tecnologia mais capital intensiva presente na maquinaria e na grande indústria.

A hipótese de Young repercutiu de tal forma que, implícita ou explicitamente, foi incorporada nos diversos modelos de desenvolvimento econômico que proliferaram nas décadas de 1940, 1950 e 1960, responsáveis pela criação da chamada “economia do desenvolvimento". Com efeito, em que pesem os distintos pressupostos e hipóteses dos modelos de big-push, de Rosenstein-Rodan (1943), de desenvolvimento com oferta ilimitada de mão de obra, de Lewis (1954), de centro-periferia, de Prebisch (1950), e de desenvolvimento impulsionado pelos efeitos de encadeamento para a frente e para trás, de Hirschman (1958), o elo comum entre eles é que a indústria, por estar sujeita a economias de escala e fomentar diversos tipos de externalidades positivas (algumas negativas, é verdade), é, portanto, a principal fonte geradora e difusora de acumulação de capital e de progresso tecnológico. Nessas condições a industrialização, ou, mais amplamente, a sofisticação produtiva (que inclui os serviços tradable sofisticados tecnologicamente, que possuem elevado valor adicionado per capita e pagam salários relativamente elevados como o faz a indústria) é o veículo que conduz e promove o desenvolvimento econômico e o processo de convergência relativa (catching $u p$ ) de um país em direção a níveis de renda per capita e de bem-estar geral compatíveis com os países considerados desenvolvidos.

No entanto, nenhum desses autores discutiu com maior ênfase o caso em que o processo de desenvolvimento, impulsionado e conduzido pela industrialização, pudesse de ser subito abortado prematuramente, quer por razões estruturais ou erros de política econômica, antes que o país tivesse logrado completar seu processo de catching up e alcançado, por conseguinte, estágio de maturidade econômica. Esta tarefa foi realizada por Nicholas Kaldor, especialmente em seus artigos clássicos de 1966 e 1970, em que justificava teórica e empiricamente por que a indústria

\footnotetext{
${ }^{8}$ Ver especialmente o Vol. I, cap. XV, “Machinery and Large-Scale Industry”. Vemos, portanto, que Marx antecipou-se a Schumpeter $(1911,1943)$.
} 
é o canal por meio do qual o processo de desenvolvimento e catching up se verifica, ao mesmo tempo em que apontava que um processo prematuro de desindustrialização ${ }^{9}$ - ou seja, da perda acentuada de participação do valor agregado industrial no total do valor agregado da economia (o seu produto interno bruto), ou alternativamente, da perda acentuada do emprego industrial no total do emprego da economia antes que o país tivesse alcançado níveis de renda per capita compatíveis com os de um país desenvolvido - poderia levar a economia de um país em desenvolvimento a um processo secular de estagnação e retardamento absoluto e relativo (falling behind) no longo prazo. As hipóteses e/ou evidências empíricas levantadas por Kaldor já foram extensamente discutidas em trabalho anterior, ${ }^{10}$ bastando aqui resumir as duas principais. A primeira diz respeito ao fato de que o setor industrial como um todo (como "macrossetor", na expressão de Kaldor, 1966), diferentemente dos setores primário e da maior parte dos segmentos do setor terciário (a exceção são os segmentos tradable do setor de serviços, como software, indústrias da tecnologia da informação e comunicação (TICs), dentre outros), por estar sujeito a economias estáticas e dinâmicas de escala, é o único capaz de disseminar seus ganhos de produtividade para o restante da economia. Em outras palavras, o setor industrial é o responsável por sustentar e realimentar o processo de desenvolvimento econômico até que o país consiga, de fato, concretizar a convergência relativa (catching $u p$ ). Somente a partir daí a maior proeminência do setor de serviços, que passa a deter elasticidade-renda da demanda no longo prazo ligeiramente superior à dos produtos industrializados, e a desindustrialização que se lhe segue devem ser entendidos como um fenômeno natural.

A segunda, e, talvez mais importante, por se tratar de uma regularidade empírica, é a forte relação de dependência - logo, mais do que uma simples correlação - do incremento da produtividade do setor industrial em relação ao próprio crescimento do produto deste setor. Embora tal evidência empírica tenha sido pioneiramente mostrada pelo economista holandês J.P. Verdoorn (1949), Kaldor (1966, p. 106) foi além, já que, influenciado pelo modelo de crescimento circular cumulativo de Myrdal (1957), argumentou que "quanto maior a taxa de crescimento do produto da economia (ou seja, do produto interno bruto), maior a tendência de crescimento da produtividade agregada". Não por acaso, os estudos empíricos que procuram testar a validade da chamada lei de Kaldor-Verdoorn (expressa pela relação entre as taxas de crescimento da produtividade e do produto) ora utilizam como variável explicativa a variação do produto industrial, ora o crescimento do PIB. ${ }^{11}$

\footnotetext{
${ }^{9}$ Kaldor (1966) não usava o termo "desindustrialização prematura”, que posteriormente ficou consagrado. No entanto, este termo já estava implícito nesse artigo pioneiro, que mostrava que o lento crescimento econômico britânico na primeira metade da década de 1960 decorria da evidência de que o setor manufatureiro inglês ficou atrasado (ou seja, desindustrializou-se prematuramente) em relação aos países desenvolvidos do período, especialmente Estados Unidos.

${ }^{10}$ Ver Nassif, Feijó e Araújo (2015).

${ }^{11}$ Para uma excelente revisão teórica e empírica da lei de Kaldor-Verdoorn, ver Ros (2014, pp. 40-49).
} 
Como acentuado anteriormente, após a revolução microeletrônica da década de 1970, diversos serviços tradable (como softwares, TICs, pesquisa e desenvolvimento etc.) vêm atuando, junto com o setor manufatureiro, no sentido de impulsionar a produtividade do trabalho, a mudança estrutural e o desenvolvimento econômico. No entanto, como mostraram Zysman et al. (2010), tais serviços raramente estão dissociados do processo fabril propriamente dito. Isso significa que, uma vez que esses serviços estão conectados às estratégias de produção das firmas e indústrias que operam tanto nos setores primário, secundário e terciário, a separação rígida entre os novos serviços tradable, de um lado - também sujeitos a economias estáticas e dinâmicas de escala -, e o setor manufatureiro propriamente dito, de outro, não é nem possível nem desejável. Nos países em que esses novos serviços tradable são expressivos - por exemplo, nos países desenvolvidos, e, na Índia, para citar um caso pontual de um país em desenvolvimento - , antes que reduzir o papel do setor manufatureiro, eles atuam como forças propulsoras complementares a este no sentido de promover a mudança estrutural, o desenvolvimento econômico e o catching $u p$.

No caso do Brasil, em particular, o processo de desindustrialização prematura - analisado na terceira seção - que começou com a Crise da Dívida Externa dos anos 1980 e se intensificou na segunda metade da década de 2000, resultou, entre outros fatores, do desmantelamento do mecanismo de neutralização da doença holandesa, em 1990, com a abertura comercial e o fim dos subsídios à exportação. A partir de então o governo mostrou incapacidade de fazer frente à tendência recorrente de apreciação crônica da taxa de câmbio real. No Brasil, esta tendência é explicada tanto por fenômenos estruturais, como a doença holandesa (agravada na segunda metade da década de 2000 pelo boom dos preços das principais commodities intensivas em recursos naturais exportadas pelo país), ${ }^{12}{ }^{13}$ quanto por políticas como o enorme diferencial entre as taxas de juros internas e internacionais, o qual induz a excessivas entradas líquidas de capitais. Ou, o que é o mesmo, pela estratégia de desenvolvimento com poupança externa (isto é, por políticas que orientaram o crescimento econômico baseado em déficits em conta-corrente financiados por poupança externa, seja sob a forma de investimentos externos diretos ou por meio de captação de recursos financeiros de curto e longo prazo via endividamento ex-

\footnotetext{
${ }^{12}$ Sobre o problema da doença holandesa no Brasil e a proposta de instrumentos para sua neutralização, ver Bresser-Pereira (2008).

${ }^{13}$ Em estudo econométrico, Nassif, Feijó e Araújo (2011) mostraram que as duas principais forças explicativas da enorme apreciação da taxa de câmbio real no Brasil entre 1999 e 2011 foram os termos de troca altamente favoráveis (decorrentes do boom dos preços das commodities exportadas) e o elevado diferencial entre as taxas de juros domésticas e internacionais (que induzem a entradas excessivas de capitais de curto prazo de natureza especulativa).
} 
terno ou emissão de bônus internacionais). ${ }^{14} 15$ Além dessas, a apreciação também foi causada pela política de usar a taxa de câmbio para controlar a inflação. ${ }^{16}$

Para um país como o Brasil, que conseguiu completar sua "revolução industrial" - para usar a expressão de um dos autores deste $\operatorname{artigo~}^{17}$-, mas não seu processo de catching up, em virtude, principalmente, do processo de desindustrialização prematura, é lícito sugerir que, para reverter o processo em curso de retardamento relativo (falling behind $),{ }^{18}$ será preciso adotar estratégias de política econômica destinadas a reindustrializar o país, o que será analisado nas próximas seções.

\section{O PROBLEMA DA REINDUSTRIALIZAÇÃO NO BRASIL: ASPECTOS ANALÍTICOS}

A estratégia de reindustrializar um país requer a mobilização de mecanismos tão complexos como a de industrialização via substituição de importações. Dentre outros, é preciso fina coordenação dos instrumentos da política macroeconômica de "curto prazo" - ou seja, das políticas monetária, fiscal, cambial e salarial, em geral introduzidas para lidar com os problemas das flutuações cíclicas de curto prazo, mas que têm efeitos poderosos sobre os resultados de longo prazo, em especial os relacionados à mudança estrutural e ao desenvolvimento econômico com os demais instrumentos de política de longo prazo, como as políticas industrial e tecnológica, educacional, de infraestrutura, etc. No que segue, discutiremos os aspectos analíticos básicos concernentes ao regime macroeconômico, para em seguida analisar os aspectos teóricos inerentes às políticas de longo prazo apropriadas para um país como o Brasil que, conquanto tenha sido bem-sucedido em promover seu processo de industrialização, não conseguiu completar seu processo de catching up. Embora essas políticas envolvam, com já dito, a mobilização do aparato educacional, de infraestrutura, mobilidade urbana, bem como as políticas industriais e tecnológicas propriamente ditas, utilizaremos a expressão política industrial para nos referir a esse conjunto de políticas, termo já consagrado pela literatura econômica.

\footnotetext{
${ }^{14}$ Para uma crítica sobre a estratégia de crescimento com poupança externa, ver Bresser-Pereira e Nakano (2003).

${ }^{15}$ Como lembra um dos autores deste artigo (Bresser-Pereira, 2015, p. 5), desde o Plano Real até o presente, a política de apreciação do real tem sido utilizada como "âncora cambial contra a inflação".

${ }^{16}$ Uma análise detalhada da taxa de câmbio como âncora da inflação no Brasil pode ser encontrada em Barbosa-Filho (2008).

${ }^{17}$ Ver Bresser-Pereira (2014). Em diversos capítulos de seu recente livro, o autor utiliza a expressão "revolução industrial” como sinônimo de industrialização ou revolução capitalista.

${ }^{18}$ Para evidências sobre o processo em curso de falling behind no Brasil no período recente, ver Nassif, Feijó e Araújo (2015).
} 


\section{O regime macroeconômico}

Da experiência exitosa de industrialização da Coreia do Sul a partir da década de 1960, bem como da capacidade - até que se prove o contrário, ainda não revertida - demonstrada pela China e Índia de sustentar a continuidade de seus respectivos processos de catching up entre a década de 1980 e final de $2000,{ }^{19}$ podemos extrair duas lições principais: i) esses países adotaram e ainda adotam políticas industriais ativas, replicando, com suas respectivas especificidades, mecanismos de proteção da indústria local e outros estímulos governamentais que já haviam sido utilizados pela maioria dos países que se desenvolveram após a Inglaterra; ${ }^{20} 21$ ii) uma política macroeconômica fundada em manter "certos" os cinco preços macroeconômicos $^{22}{ }^{23}$ e orientada simultaneamente para o desenvolvimento e para a estabilidade dos indicadores domésticos e externos da economia sempre foi peça integrante fundamental para assegurar os resultados positivos almejados pela política industrial, em especial, a mudança e diversificação da estrutura produtiva, o aumento da produtividade absoluta e relativa e o aumento da participação na cesta de produtos exportados de bens de maior sofisticação tecnológica e elevada elasticidade-renda da demanda no longo prazo.

Com relação ao regime macroeconômico, cabe destacar que a posição dos economistas keynesianos-estruturalistas - ou, o que é o mesmo, desenvolvimentistas - é bem distinta do chamado "novo consenso macroeconômico", que, aliás, já se tornou "velho" após a crise financeira global de 2008. Como salientam Blanchard et al. (2010, 2013), o referido consenso se ancorava no pressuposto de que o controle da inflação deveria ficar sob o âmago estrito da política monetária que, por meio de um único instrumento (a taxa básica de juros de curto prazo, ou policy-rate), se encarregaria de manter estável o nível geral de preços.

A posição dos economistas desenvolvimentistas, a esse respeito, é bem distinta.

\footnotetext{
${ }^{19}$ Ver Nassif, Feijó e Araújo (2015a).

${ }^{20}$ A diferença é que, após as negociações da Rodada Uruguai, de que resultou a instituição da Organização Mundial do Comércio (OMC), em 1995, diversos estímulos passaram a ser proibidos ou sujeitos a controvérsias no âmbito das novas regras multilaterais.

${ }^{21}$ Para a experiência exitosa de desenvolvimento da Coreia do Sul, ver o magistral livro de Alice Amsden (1989). Em livro posterior, Amsdem (2001: 85) mostrou que, “como estratégia de catching up, políticas de livre comércio parecem ter-se limitado à Suíça e Hong-Kong”. (Chang 2003, p. 2) também enfatizou que a maioria dos países desenvolvidos "adotou políticas industriais e comerciais consideradas 'ruins' na avaliação da corrente neoclássica, tais como proteção à indústria nascente e subsídios às exportações”.

22 Segundo Bresser-Pereira, Oreiro e Marconi (2014, p. 13), os cinco preços macroeconômicos fundamentais são (todos expressos em termos reais) "a taxa de lucro, a taxa de câmbio, a taxa de juros, a taxa de salários e a taxa de inflação".

${ }^{23}$ Nesses países, no processo bem-sucedido de catching up, a taxa de lucro foi mantida satisfatória para as empresas; o nível da taxa de juros real, baixo; a taxa de câmbio real, competitiva (porque tornava competitivas as empresas industriais que utilizavam tecnologia no estado da arte mundial); a taxa de inflação, baixa; e a taxa de salários, compatível com a taxa de lucro satisfatória, ou seja, aumentando com a produtividade.
} 
O papel da política monetária não deveria ser apenas perseguir metas de inflação baixas e estáveis, mas também metas de crescimento econômico sustentáveis mediante a suavização das flutuações cíclicas. Essa posição, aliás, não é monopólio dos economistas estruturalistas, posto que, em artigo recente, Janet Yellen (2014, p. 31), a presidente do Federal Reserve Bank dos Estados Unidos (FED), defendeu com veemência que "os bancos centrais deveriam desenhar políticas monetárias destinadas a perseguir metas de inflação em que os objetivos de manter a estabilidade de preços não se sobrepusessem aos de alcançar o pleno-emprego".

Em termos gerais, um regime de política macroeconômica orientado para a promoção e continuidade do processo de catching up deve se caracterizar por uma política fiscal contracíclica (isto é, equilíbrio ou superávits fiscais primários nas expansões e redução destes ou mesmo déficits primários nas recessões), por uma política monetária que mantenha as taxas de juros reais médias abaixo da taxa de retorno real média sobre o capital da economia como um todo, e que, combinada com políticas macroprudenciais, controle a inflação no longo prazo; por uma política salarial que contribua para que a taxa de salários aumente de acordo com o incremento da produtividade ; e por uma política cambial que mantenha a taxa de câmbio real competitiva e estável (isto é, que flutue em torno da taxa de câmbio de equilíbrio industrial, que torna competitivas as empresas de bens e serviços tradable não commodities que utilizem tecnologia no estado da arte mundial.. ${ }^{24} \mathrm{~A}$ capacidade de os policymakers manterem esses preços macroeconômicos fundamentais em torno de seu nível apropriado é condição sine qua non para a redução dos custos de oportunidade dos investimentos em criação e expansão de capacidade produtiva, bem como em inovações tecnológicas.

Nenhuma política industrial conseguirá ser bem-sucedida no objetivo de promover a mudança estrutural e o processo de catching up se aqueles preços macroeconômicos (inflação, taxa de juros real, taxa de câmbio real e taxa de salários reais) não estiverem em seu níveis corretos. Para os países em desenvolvimento, a taxa de câmbio real afigura-se como um dos mais estratégicos para que a economia continue sua trajetória de catching $u p$, em virtude de seus impactos diretos e indiretos sobre diversas outras variáveis micro e macroeconômicas. Bresser-Pereira, Oreiro e Marconi (2014, pp. 10-11) justificam de forma precisa o caráter estratégico da taxa de câmbio real na promoção do desenvolvimento econômico:

\footnotetext{
${ }^{24}$ Uma taxa de câmbio real competitiva é compatível tanto com a "taxa de equilíbrio industrial" proposta por Bresser-Pereira $(201,2014)$, ou seja, aquela que incentiva as firmas domésticas a adotarem tecnologias no estado da arte, como com a "taxa de câmbio real 'ótima' de longo prazo" proposta por Nassif, Feijó e Araújo (2011), isto é, aquela que, por incentivar a alocação de recursos dos setores de baixa para os de alta produtividade, assegura e sustenta, ceteris paribus, o desenvolvimento econômico. Em face da similaridade de ambos os conceitos, utilizaremos, doravante, a expressão "taxa de câmbio de equilíbrio industrial” para nos referirmos à taxa de câmbio real considerada competitiva.
} 
As variáveis macroeconômicas-chave, além da taxa de investimento, são o déficit em conta-corrente e a taxa de câmbio $[. . .]^{25}$. As importações, as exportações, a taxa de investimento, a taxa de poupança e a inflação dependem dela [da taxa de câmbio real]. Os investimentos também, porque podemos pensar a taxa de câmbio como o interruptor de luz que conecta ou desconecta as empresas eficientes existentes num país dos mercados externos e de seus próprios mercados internos.

A teoria convencional assevera que um regime de câmbio flutuante é eficaz para amortecer choques e promover o ajustamento automático e a estabilidade do balanço de pagamentos no curto e no longo prazo. Na prática, isso não parece ser verdade para a maioria dos países em desenvolvimento. No caso do Brasil, em particular, mesmo o regime de câmbio flutuante, introduzido em 1999, não tem sido suficiente para impedir uma tendência recorrente de apreciação crônica da moeda brasileira em termos reais, porque, conforme tem reiterado um dos autores deste trabalho (Bresser-Pereira, 2010, 2015), não obstante o país incorra em déficits em conta-corrente crescentes e no aumento que deveria ser preocupante da dívida externa, os credores externos continuam a transferir capitais para o país, consubstanciando-se, assim, um processo de bolha de crédito ou de financeirização.

$\mathrm{Na}$ experiência brasileira recente, a estratégia de crescer com poupança externa - ou o que é o mesmo, de financiar os déficits em conta-corrente com capitais externos de diferentes rubricas - e o uso da taxa de câmbio real como âncora da inflação estão relativamente interligados. No campo do debate ortodoxo, a taxa de câmbio é simplisticamente avaliada como o preço que assegura o ajustamento do balanço de pagamentos no curto e no longo prazos. Deve-se lembrar, entretanto, que o modelo Mundell-Fleming, que avaliza tal resultado, descarta uma variável fundamental: o tempo. Ou seja, seguindo Mundell-Fleming, um déficit do balanço de pagamentos tenderia, simultaneamente, a depreciar a moeda, deslocar a curva IS (investment-saving) para a direita (via aumento das exportações líquidas, uma vez satisfeita a condição de Marshall-Lerner), garantindo, em última instância, maior crescimento econômico e o ajuste do balanço de pagamentos.

O problema é que o mundo real é bem diferente e o caso brasileiro tem sido paradigmático a esse respeito. Partindo-se de uma situação inicial em que o balanço de pagamentos brasileiro se encontre em equilíbrio (digamos, em 2005, porque uma crise financeira em 2002 causou forte depreciação cambial), como as taxas de juros domésticas têm sido invariavelmente bem superiores às internacionais - em virtude da política monetária brasileira, que tem sido incapaz de reduzir estrutural e definitivamente as taxas de juros -, nas fases de relativa estabilidade macroeconômica os vultosos influxos líquidos de capitais (parte significativa dos quais sob as modalidades de capitais para aplicação em portfólio de curto prazo ou empréstimos

\footnotetext{
${ }^{25}$ Neste artigo, além da taxa de câmbio real, nossa ênfase recairá nos seguintes preços macroeconômicos: a taxa de juros real e a taxa de salários reais.
} 
intercompanhias, ambas de natureza altamente volátil e especulativa) acabam por apreciar a moeda doméstica em termos nominais e reais.

Desde a introdução do regime de metas de inflação, foi tal apreciação perversa e não a política de juros ou monetária propriamente dita que assegurou que a inflação, salvo exceções, tenha ficado dentro do intervalo de tolerância do centro da meta inflacionária perseguida pelo Banco Central. ${ }^{26}$ Enquanto os especuladores internacionais avaliarem o déficit em conta-corrente que se retroalimenta com a apreciação cambial como "manejáveis", eles seguem apostando que o real brasileiro continuará apreciando no futuro até que o país entre em crise de balanço de pagamentos.

No caso da doença holandesa, que, no Brasil, agravou-se sobremaneira durante o ciclo de boom dos preços das commodities no mercado internacional, enquanto o processo de reindustrialização não lograr o objetivo de promover uma mudança significativa da estrutura produtiva e da pauta exportadora para bens e serviços de média e alta sofisticação tecnológica - e que, por isso, diferentemente das commodities, têm seus preços determinados por estratégias price-makers (logo, flutuam muito pouco nos mercados globais) - será preciso introduzir mecanismos que neutralizem seus efeitos sobre a apreciação cambial. Como ocorreu na década de 2000 no Brasil, a ascensão quase contínua do preço das commodities exportadas pelo país acarretou enorme incremento de rendas ricardianas que - aliado a outros fatores - , tendo provocado enorme aumento da demanda relativa de serviços nontradable, acabou por contribuir - junto com as expressivas entradas líquidas de capitais externos - para o aumento de seus respectivos preços relativos e, consequentemente, para a apreciação da moeda brasileira em termos reais. Como tem proposto um dos autores deste artigo (Bresser-Pereira, 2008; Bresser-Pereira, Oreiro e Marconi, 2014), um dos mecanismos para neutralizar os impactos nefastos da doença holandesa poderia ser a introdução de uma retenção cambial ou imposto incidente sobre as rendas dos exportadores que operam nos setores de commodities. Tal imposto variaria de um mínimo de $0 \%$, quando o preço da respectiva commodity estivesse orbitando em torno de seu nível de equilíbrio de longo prazo, a um máximo percentual correspondente ao preço que excedesse este nível. Essa foi a política que o Brasil usou de maneira relativamente disfarçada durante todo o período de industrialização acelerada, e que os cafeicultores denominavam "confisco cambial", embora eles, afinal, não fossem prejudicados por ela, porque o que pagavam em termos de retenção correspondia aproximadamente ao que ganhavam com a consequente depreciação.

\footnotetext{
${ }^{26}$ Cabe lembrar que, nos 17 anos de existência do regime de metas de inflação (1999-2015), o Brasil só conseguiu alcançar o centro da meta durante quatro vezes (em 2000, 2006, 2007 e 2009). Na maior parte dos casos, entretanto, a meta foi cumprida, mas ficou mais próxima do teto máximo de tolerância do que do centro da meta. Pelas regras do Conselho Monetário Nacional (CMN) - formado pelos ministros do Planejamento, da Fazenda e pelo presidente do Banco Central do Brasil, e que define a meta de inflação anual - a meta é considerada cumprida desde que fique dentro do intervalo de tolerância.
} 


\section{Política industrial para a reindustrialização}

Do que foi analisado até aqui, é lícito depreender que a política macroeconômica que mantenha corretos os preços macroeconômicos é a política central para promover a mudança estrutural e o catching up. Mas, a ela devemos acrescentar a política industrial, não como um substituto do regime macroeconômico, mas como um complemento estratégico. Não vamos tecer comentários sobre os argumentos teóricos em prol da política industrial. Como sugere o título pragmático de um artigo de Rodrik (2008), "Industrial policy: don't ask why, ask how", os argumentos a favor da adoção de políticas industriais são irrefutáveis.

Antes de passarmos à análise das propostas de política propriamente dita, cabe discutir brevemente qual deveria ser o foco de uma política industrial voltada para a reindustrialização de um país como o Brasil que se encontra em processo contínuo de falling-behind (Nassif, Feijó e Araújo, 2015). Uma vez que o Brasil já cumpriu sua etapa de industrialização, devemos descartar, de antemão, argumentos e mecanismos de política voltados para "indústrias nascentes" (infant industries), à exceção de poucos segmentos na área de alta tecnologia, como será sugerido adiante. Similarmente, devem ser deixadas de lado políticas que há muito se tornaram obsoletas do velho modelo de substituição de importações, em especial, a ideia equivocada de que diversificação produtiva (em especial do setor industrial) seja sinônimo de quase autarquia, ou seja, de internalizar a produção da quase totalidade dos bens segundo categorias de uso (bens finais - de consumo ou de capital - e bens intermediários). Como já mostrara Maria da Conceição Tavares (1963) em seu trabalho clássico, o "modelo de substituição de importações” já se havia esgotado no final da década de 1950, com o Plano de Metas (1956-1960), justamente porque a substituição de bens importados por produção local em determinado segmento acabava por ensejar e acelerar o incremento da demanda de bens de capital e bens intermediários ali utilizados, de sorte que, no limite, não havia (e nem seria desejável sob a ótica da eficiência microeconômica) como substituir todas as compras externas por produção local.

Sendo assim, uma política industrial voltada para a reindustrialização deve evitar o uso abusivo da proteção tarifária às importações, como ocorreu no período da substituição de importações. Isso não significa que o uso da proteção tarifária deva ser totalmente descartado, como sugeriram Hausmann e Rodrik (2003). Segundo esses autores, em vez de proteção tarifária, que não é capaz de separar os verdadeiros inovadores dos imitadores, seria preferível que os mecanismos de estímulo às inovações se concentrassem no crédito público (das agências governamentais ou bancos estatais de desenvolvimento). Eles argumentam, corretamente, que eventual proteção tarifária pode estimular excesso de entrada prematura de firmas imitadoras em setores sujeitos a economia de escala, antes que as verdadeiras empresas inovadoras tenham tido tempo suficiente não apenas para recuperar os sunk costs relacionados às atividades pregressas de $\mathrm{P} \& \mathrm{D}$, como para alcançar as escalas mínimas eficientes necessárias para se manterem competitivas no mercado. No entanto, é preciso lembrar que uma tarifa de livre 
comércio (ou seja, zero), introduzida na fase em que empresas inovadoras estejam tentando difundir seus produtos no mercado, por estimular maior penetração de produtos importados substitutos próximos, pode drenar todos os esforços de busca tecnológica dos inovadores, antes que estes tenham tempo hábil de percorrer a curva de aprendizado tecnológico e difundir seus novos produtos no mercado. Numa palavra, a tarifa de importação aos setores incentivados para fins de inovação deve ser moderadamente baixa e cadente ao longo do tempo, porém de magnitude suficiente para, supondo que a taxa de câmbio real esteja em seu nível competitivo (no “equilíbrio industrial”), não abortar a difusão dos bens inovados no mercado.

No entanto, permanece ainda poderoso o argumento de que um processo de reindustrialização, para que seja bem-sucedido num país que ainda não completou seu processo de catching up, não deve abandonar o objetivo de manter o processo de diversificação industrial, renunciando, portanto, à tentação de adesão precoce a propostas de integração nas "cadeias globais de valor", o que, na prática corresponderia a aderir a estratégias radicais de especialização em processos produtivos (notadamente industrial). De fato, é verdade que o acirramento da concorrência internacional, que se seguiu à confluência de eventos posteriores à década de 1970 (revolução microeletrônica, intensa liberalização dos fluxos de comércio de bens e de capitais etc.), implicou uma enorme fragmentação global da produção das empresas multinacionais - que passaram a localizar a produção de bens finais, partes, peças e componentes em diferentes países da economia mundial, com base em fatores diversos como o custo relativo da mão de obra, oferta de matérias-primas, qualidade da infraestrutura, grau de liberalização comercial etc. No entanto, como lembrou Rocha (2015), diversos pesquisadores das Universidades de Cambridge (UK), Harvard e Massachusetts Institute of Technology (MIT) têm questionado os efeitos positivos decorrentes dessa nova lógica de fragmentação produtiva, argumentando que ela

tem causado danos em partes do sistema industrial, como redução das operações por fornecedores locais, queda na produção de componentes e novas tecnologias, declínio das habilidades relacionadas à engenharia de produção (particularmente know-how da manufatura), assim como deterioração dos processos de prototipagem, testes e projetos pilotos de produtos manufaturados.

E, mais importante, Rocha (ibidem) comenta que

os proponentes da chamada visão pró-manufatura [poderíamos dizer, os kaldorianos] têm alertado para o fato de que economias que se concentram apenas em atividades complementares à produção (e abandonam a manufatura per se) podem apresentar deterioração da interdependência entre as atividades de produção e sua capacidade de gerar inovação tecnológica.

Ademais, como mostrou o influente artigo de Imbs e Wacziarg (2003), baseado num ampla amostra de países, existe uma regularidade empírica inquestionável 
segundo a qual à medida que os países avançam no processo de catching up, aumenta consideravelmente o grau de diversificação industrial, que só tende a reduzir quando os países já tenham conseguido alcançar elevado estado de maturidade tecnológica e de renda per capita. Assim, esse estudo revela que, ao contrário das predições de especialização emanadas da teoria das vantagens comparativas, a relação entre o grau de concentração produtiva e nível de renda per capita tem o formato de uma curva em U, como pode ser observado no Gráfico 1.
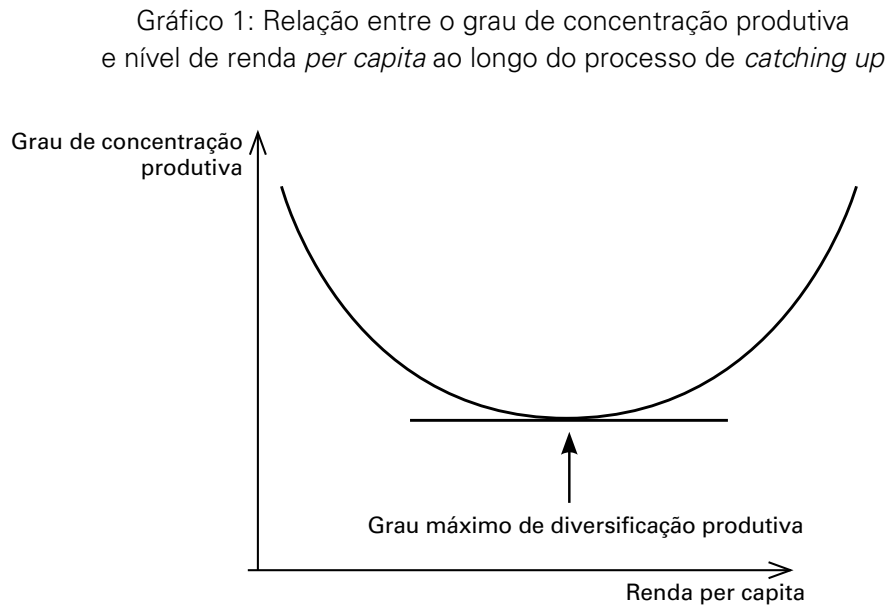

Fonte: Elaboração própria, baseado em Imbs e Wacziarg (2003)

Por outro lado, ainda que tenhamos afirmado anteriormente que a abordagem desenvolvimentista advoga que a política industrial não se limite à abrangência horizontal, seria o caso de se perguntar se uma política industrial orientada para a reindustrialização no Brasil ainda deveria conter algum foco de natureza setorial. Rodrik (2004) argumenta corretamente que uma política industrial num país em desenvolvimento deveria ter como foco principal a inovação [o autor não sugere, mas acrescentaríamos, inovação em processos e em produtos], pois é nessa atividade que se concentram problemas graves de insuficiência de demanda por parte dos empresários. E, ademais, como já afirmamos, se esse país tem sua moeda cíclica e cronicamente apreciada em termos reais, o problema seria ainda agravado não apenas devido à insuficiência de demanda, como também ao acesso a esta (BresserPereira, 2014, pp. 154-159). Nesse caso, segundo Rodrik (2004), o papel do governo é contribuir para que os empresários possam "descobrir" as atividades inovadoras com maior potencial de sucesso e retorno, bem como solucionar os problemas de insuficiência ou racionamento de crédito. Da mesma forma, tem também razão o autor ao defender como segundo foco da política industrial a concentração do governo em atividades com amplo potencial de incrementar a produtividade e de gerar externalidades econômicas positivas, tais como educação, infraestrutura, saúde, mobilidade urbana e logística.

Porém, não é convincente o argumento do autor segundo o qual as políticas 
industriais deveriam focar essencialmente atividades e tecnologias, mas não setores. A principal razão apontada por Rodrik (2004, p. 14, tradução livre do original) é que

o que precisa de apoio [governamental] não são setores específicos per se, mas tecnologias específicas ("type of technologies") que, por se caracterizarem por economias de escala ou economias de aglomeração [ou seja, clusters], poderiam fracassar no processo de catching up na falta de suporte público.

O argumento não convence, porque as tecnologias estão, salvo exceções, intimamente associadas a cadeias e setores produtivos específicos, sejam eles da agricultura, indústria ou mesmo do setor de serviços. Como enfatiza Ocampo (2005), a dinâmica das estruturas produtivas decorre da interação entre atividades, firmas, setores e instituições (ênfase nossa). O que costuma ocorrer na prática é, ao contrário do que supõe Rodrik (2004), algumas tecnologias abarcarem diversos setores com vínculos diretos e indiretos entre si, de tal sorte que, nesses casos, é comum se referir a estes não como um setor, mas como um complexo de indústrias, como ocorre com o complexo eletrônico - que abarca um conjunto de indústrias tradicionais (eletrônica de consumo) e outras que se firmaram após a revolução microeletrônica (informática, incluindo hardware e software; componentes eletrônicos, equipamentos de telecomunicações etc.). ${ }^{27}$

Assim, por exemplo, por contar com vastos e diversificados recursos naturais vinculados à biotecnologia (em especial, vasta e diversificada fauna e flora, além de recursos minerais), o desenvolvimento dessas atividades requererão algum grau de intervenção moderado para estimular os setores a elas relacionados, tais como as indústrias química, bioquímica e farmacêutica, por meio da combinação de mecanismos horizontais com estímulos diretos aos setores mencionados.

Outra questão que nos tem sido cara é a falta de rigor na cobrança de resultados por parte das empresas que recebem todo tipo de incentivo público, como créditos oficiais, subsídios, isenções tributárias ou mesmo alguma proteção tarifária às importações. Em que pesem as sugestões feitas nesse sentido, ${ }^{28}$ mesmo após a retomada da política industrial no Brasil, a partir de 2003, com a Política Industrial, Tecnológica e de Comércio Exterior (PITCE), muito pouco tem sido feito no sentido de cobrar resultados por parte das empresas incentivadas, evitar corrupção e atividades rent-seeking, bem como fomentar contrapartidas (transferência de tecnologia para firmas locais, transbordamento tecnológico para outros setores, dentre outras) por parte das empresas multinacionais já instaladas ou prestes a se instalar no Brasil, como fazem à exaustão os países asiáticos. ${ }^{29}$ Comparado a países como China e Índia, que procuram

\footnotetext{
${ }^{27}$ Sobre a história do complexo eletrônico brasileiro, ver Nassif (2002).

${ }^{28}$ Ver por exemplo um longo artigo de um dos autores deste estudo, publicado em setembro de 2003 (Nassif, 2003).

${ }^{29}$ Note que estamos usando o verbo “fomentar”, em lugar de "exigir”, uma vez que exigências podem
} 
orientar os setores prioritários e a localização geográfica interna para fins de atração de investimento estrangeiro, bem como exigir das empresas multinacionais alguma forma de contrapartida tecnológica ou exportadora, o Brasil pode ser considerado uma verdadeira "casa da mãe Joana". Com respeito às exigências de desempenho pelas empresas que recebem incentivos públicos, Rodrik (2004) comenta que há indicadores muito fáceis de serem computados, como, por exemplo, a variação da produtividade do trabalho ao longo do tempo.

\section{CONCLUSÃO}

Neste artigo mostramos que países que, por distintas razões, tiveram abortado seu processo de catching up devem continuar perseguindo o objetivo de restaurá-lo mediante estratégias nacionais de reindustrialização. Embora tais estratégias devam se orientar por políticas industriais apropriadas, bem desenhadas e bem implementadas, estas não mostrarão resultados promissores se não forem coordenadas com um regime macroeconômico consistente.

Um regime macroeconômico consistente é aquele que, além de manter a estabilidade de preços e fiscal, consegue engendrar políticas econômicas que viabilizem taxas de juros reais médias inferiores à taxa de retorno real média sobre o capital, taxas de câmbio reais competitivas (no nível do "equilíbrio industrial”) e taxas de salários que cresçam de acordo com crescimento da produtividade. Na prática, nenhuma dessas condições foi preenchida no Brasil nas últimas décadas. Daí, a desindustrialização prematura, baixa produtividade e baixo crescimento observados em igual período. Em artigo subsequente proporemos, com algum nível de detalhamento, medidas concretas para restaurar a conexão entre o regime macroeconômico e a política industrial no Brasil, visando não apenas a propiciar a reindustrialização, como a retomar o processo de crescimento econômico sobre bases sustentáveis. Só assim o país poderá almejar retomar o processo de catching up, que foi interrompido no início da década de 1980.

\section{REFERÊNCIAS BIBLIOGRÁFICAS}

Amsdem, A. H. (1989). Asia's next giant: South Korea and late industrialization. Oxford: Oxford University Press.

Amsdem, A. H. (2001). The rise of "the rest": challenges to the west from late-industrializing economies. Oxford: Oxford University Press.

Arezki, R., e. Dumitrescu, A. Freytag, A. e M. Quintyn (2012) "Commodity prices and exchange rate volatility: lessons from South Africa's capital account liberalization”. IMF Working Paper WP/12/168. Washington, D.C.: International Monetary Fund.

ser refratárias às regras multilaterais de comércio sob a égide da OMC. 
Barbosa-Filho, N.H. (2008) "Inflation targeting in Brazil: 1999-2006". International Review of Applied Economics, Vol. 22, n 2: 187-200.

Blanchard, O., G. Dell'Ariccia, e P. Mauro (2010). "Rethinking macroeconomic policy". IMF Staff Position Note SPN 10/03. Washington, D.C.: International Monetary Fund.

Blanchard, O., G. Dell'Ariccia, e P. Mauro (2013) “Rethinking macro policy II: getting granular”. IMF Staff Discussion Note SDN 3/03. Washington, D.C.: International Monetary Fund.

Bresser-Pereira, L.C. (2008) “The Dutch disease and its neutralization: a Ricardian approach”. Revista de Economia Política, Vol. 28, n 1 (109): 47-71.

Bresser-Pereira, L.C. (2010) Globalization and Competition. Why some emerging countries succeed while others fall behind. Cambridge: Cambridge University Press.

Bresser-Pereira, L.C. (2014) A Construção Política do Brasil: Sociedade, Economia e Estado desde a Independência. São Paulo: Ed. 34.

Bresser-Pereira, L.C. (2015) "Reindustrialização como projeto nacional”. Le Monde Diplomatique Brasil. Outubro: 4-5.

Bresser-Pereira, L.C. e Y. Nakano (2003) “Crescimento econômico com poupança externa?”. Revista de Economia Política, Vol.23, n 2(90): 3-27.

Bresser-Pereira, L.C., J. L. Oreiro, e N. Marconi (2014) Developmental Macroeconomics: New Developmentalism as a Growth Strategy. London: Routledge.

Chang, H.J. (2003) Kicking away the Ladder: Development Strategy in Historical Perspective. London: Anthem Press.

Furtado, C. (1959[1982]) Formação Econômica do Brasil. 18a. ed. Cia Editora Nacional.

Hausmann, R. e D. Rodrik (2003) "Economic development as self-discovery". Journal of Development Economics, Vol. 72, Issue 2, December: 603-633.

Hirschman, A. O. (1958). The Strategy of Economic Development. New Haven: Yale University Press.

Imbs, J. e R.Wacziarg (2003) "Stages of diversification". American Economic Review, Vol. 93, n 1, March: 63-86.

Kaldor, N. (1966). Causes of the Slow Rate of Economic Growth of the United Kingdom. An Inaugural Lecture. Cambridge : Cambridge University Press.

Kaldor, N. (1970). “The case for regional policies”. Scottish Journal of Political Economy, vol. 17 (3), pp. $337-48$

Lewis, W. A. (1954). "Economic development with unlimited supplies of labor". Manchester School of Economic and Social Studies, 22 (2): pp.139:191.

Lisboa, M. (2014). "Desenvolvimento condena país a um PIB medíocre, diz ex-secretário da Fazenda”. Entrevista ao Valor Econômico, 8 de janeiro de 2014.

Marx, K. (1887 [1990]). The Capital. A Critical Analysis of Capitalist Production. Vol. I. First English edition, edited by Frederick Engels. London: Penguin Books.

Myrdal, G. (1957). Economic Theory and Underdeveloped Regions. London: Duckworth.

Nassif, A. (2002). "O complexo eletrônico brasileiro" In: BNDES 50 Anos: Histórias Setoriais. Rio de Janeiro: Banco Nacional de Desenvolvimento Econômico e Social.@@ página

Nassif, A. (2003). "Uma proposta de política industrial para o Brasil: objetivos, critérios e setores prioritários”. Revista do BNDES, Vol. 10, n 20, dezembro: 79-120.

Nassif, A., C.Feijo, e E.Araújo (2015) "Structural change and economic development: is Brazil catching-up or falling-behind?”. Cambridge Journal of Economics. Vol. 39, September: 1307-1332.

Nassif, A., C. Feijo, e E. Araújo (2015a). “The BRICS’s long term economic performance”. Artigo preparado para a 19th Annual Conference of the Research Network Macroeconomics and Macroeconomic Policies ("FMM Conference: The Spectre of Stagnation? Europe in the World Economy/ Area: Comparison of Economic Performance in Different Parts of the World”), Berlin, Germany, 22-24 October, 2015. Website: http://www.boeckler.de/veranstaltung_imk_53337.htm. Acessado em 17 de dezembro de 2015.

Nassif, A., C. Feijo, e E. Araújo (2011). “The Long-term "Optimal” Real exchange rate and the currency overvaluation trend in open emerging economies: the case of Brazil". UNCTAD Discus- 
sion Papers $\mathrm{n}^{\circ}$ 206. Geneva: United Nations Conference on Trade and Development (UNCTAD). December (available at http://unctad.org/en/pages/publications/Discussion-Papers-(Series).aspx).

Ocampo, J. A. (2005). "The quest for dynamic efficiency : structural dynamics and economic growth in developing countries”. In J. A. Ocampo (ed.) Beyond Reforms: Structural Dynamics and Macroeconomic Vulnerability. Washington, DC: World Bank Publications, 2005: 3-43.

Prebisch, R. (1950). The Economic Development of Latin America and its Principal Problems. New York: United Nations.

Rocha, I. (2015). “Dinamismo industrial e cadeias globais de valor". Valor Econômico, 30 de março de 2015.

Rodrik, D. (2004). "Industrial policy for the twenty-first century". Harvard University Discussion Paper 4767. Center for Economic Policy Research. November.

Rodrik, D. (2008). “Industrial policy: don't ask why, ask how”. Middle East Development Journal, Demo Issue (2008): 1-29

Ros, J. (2014). Productividad Y crecimiento em América Latina: por qué la productividad crece más en unas economias que en otras? Desarrollo Económico. México, D.F.: Naciones Unidas/Comisión Económica para América Latina y el Caribe (CEPAL).

Rosenstein-Rodan, P. N. (1943). "Problems of industrialization of eastern and south-eastern Europe". Economic Journal, 53: 202-211.

Schumpeter, J. A. (1911). Teoria do Desenvolvimento Econômico [Trad. De Theorie der Wirtschaftliche Entwicklung]. São Paulo: Ed. Abril Cultural, 1982.

Schumpeter, J. A. (1943). Capitalism, Socialism and Democracy. London and New York: Routledge (1994 edition).

Smith, A. (1776). An Inquiry into the Nature and Causes of the Wealth of Nations. New York: Modern Library, 1937.

Suzigan, W. e A. Villela (1997). Industrial Policy in Brazil. Campinas: Editora Unicamp.

Tavares, M.C. (1963). “Auge e declínio do processo de importações no Brasil”. In: M.C. Tavares (org.). Da Substituição de Importações ao Capitalismo Financeiro. 10ª ed. Rio de Janeiro: Zahar Editores.

Verdoorn, P. J. (1949). "Fattori che regolano lo sviluppo della produttivitá del lavoro. L'Industria. Republicado como "Factors that Determine the Growth of Labour Productivity". In: L. Pasinetti (ed.), Italian Economic Papers, Vol. II, Oxford: Oxford University Press, 1993.

Wade, R. (1990). Governing the Market: Economic Theory and the Role of Government in East Asian Industrialization. Princeton: Princeton University Press.

Yellen, J. (2014). “Many targets, many instruments: where do we stand?” In: G. Akerlof, O. Blanchard,D. Romer e J. Stiglitz. What Have We Learned? Macroeconomic Policy after the Crisis. Cambridge, MA: The MIT Press.

Young, A. A. (1928). "Increasing returns and economic progress". The Economic Journal 152 (XXXVIII): 527-542. December.

Zysman, J., S. Feldman, J. Murray, N.C. Nielsen, e K.E. Kushida (2010). “Services with everything: The ICT-Enabled digital transformation of services”. BRIE Working Paper 187a. 